\title{
Utilization of plant resources in Dang district, West Nepal
}

\author{
S. R. Sigdel ${ }^{1}$ and M.B. Rokaya ${ }^{2}$
}

\begin{abstract}
This paper aims to highlight the uses of forest resources in Purandhara, Panchakule and Goltakuri Village Development Committees (VDCs) of Dang district, western Nepal. The ethnobotanical data was collected through Participatory Rural Appraisal (PRA) that involved discussion with local people and key informants, through semi-structured questions and informal conversations. Vulnerability of plants used in the study area was assessed by adapting the Rapid Vulnerability Approach (RVA). Altogether 85 plant species belonging to 79 genera and 56 families were recorded in the study areas. Twelve plant species were found to be used for various purposes other than medicinal. They were used as food, fodder, in construction, in religious purposes and even in yielding dyes. Seventy three plant species were found to be medicinal in properties for treating 144 different ailments. Remedies for 27 ailments were reported as new uses. The most common way of admission of medicine was oral $(76.71 \%)$ followed by external or topical (35.6 \%) and nasal (1.27 \%). The RVA test showed Dalbergia sissoo (with 15 scores) and Terminalia alata (with 14 scores) as most vulnerable ones.
\end{abstract}

Key words: Dang district, ethnobotany, medicinal plants, vulnerability test

$\mathbf{T}$ here are many researches related to ethnobotany carried out in Dang district (Manandhar, 1985; Acharya, 1996; Adhikari, 1997; Adhikari, 1998; Poudel, 2000). Such researches are found to be focused mainly on uses of the plants for medicinal purpose only. However, a study related to uses of plants for various purposes (including medicinal) would also be of great importance in the field of ethnobotany. Furthermore, use of analytical tools to prioritize certain species for conservation is instrumental in ethnobotanical studies (Lama et al., 2001; Rokaya, 2002; Ghimire and Aumeeruddy-Thomas, 2005; Wagner et al., 2008; Rokaya et al., 2010). Such tools play important role in setting conservation goals.

In this study, the researchers attempted to collect and document indigenous ethnobotanical information from Dang District of Western Nepal. The researchers specifically, focused on seeking the answers for: (I) What is the diversity of plants in Dang district? (II) What are the different uses of plants and how are they administered for herbal medicine? and (III) What are the most important medicinal plants that are needed for conservation?

\section{Materials and methods}

\section{Study area}

The study was carried out in the Purandhara, Panchakule and Goltakuri VDCs lying in Dang district of Western Nepal. The population of the area is 21258 people (CBS, 2001). The altitudinal variation ranges from 200 to $1400 \mathrm{~m}$ above sea level. The vegetation comprises mainly of tropical type (Chaudhary, 1998). Major vegetation of the zone includes: Sal (Shorea robusta) forest, tropical deciduous riverine forest and tropical evergreen forest. Sal forest has mainly pure stands of Shorea robusta. Some of the other species, inter alias, include: Terminalia bellirica, T. chebula, and Adina cardifolia. Along the streams and valleys, sal forest is replaced by the tropical deciduous riverine forest. Tropical deciduous riverine forest and tropical evergreen forest compose tress like: Aegle marmelos, Albizia spp, Baubinia variegata, Dalbergia latifolia, Symplocas ramosissima, Lagerstroemia parvifolia, Toona serrata, Justicia adhatoda, Hypericum cordifolium, Clerodendron viscosum and Baubinia vablii, Bombax ceiba, Zisyphus mauritiana. In poorly drained areas, large stretches of Saccharum bengalense and Saccharum spontaneumi are predominantly found studded with clumps of Acacia catechu and Dalbergia sissoo (Chaudhary, 1998).

\footnotetext{
${ }^{1}$ Forest Resource Assessment (FRA) Nepal. Email: sigdelshalik@gmail.com

2 Department of Ecology/Botany, Faculty of Sciences, Charles University, Praha, Czech Republic
} 


\section{Data collection}

The field visit was carried out in November 2007 for 9 days. The data were collected through Participatory Rural Appraisal (PRA) which included discussion with local people and key informants, through semi-structured questions and informal conversations (Martin, 1995). The information collected was on: uses of plants, modes of preparation, administrations and the parts used. The vernacular names were determined with the help of local people. The informants were around 50 people including traditional healers, firewood collectors, farmers, teachers, household heads and many villagers. The age of the informants ranged from 20 to 69 years. The information on plants were cross-checked twice or thrice for each plant at different places. Herbarium specimens were not collected for the commonly known plants. However such specimens were collected for all dubious species and were pressed and dried in the field. Scientific names were determined by using different literatures (Polunin and Stainton, 1984; Lama et al., 2001; Manandhar, 2002; Baral and Kurmi, 2006). Nomenclature of Press et al. (2000) was followed.

The ethnobotanical information was categorized into seven classes: medicinal, food, fodder, construction, fiber, religious and others (colouring, dyes). The medicinal uses were further classified into nine diseases: circulatory, digestive, excretory, muscular, nervous, respiratory, reproductive, skeletal systems and others (cough cold, cuts, wounds, lactation, eye problems, etc.)

\section{Data analysis}

There are many tools that are used in selecting the most used plants (Lama et al., 2001; Rokaya, 2002; Hoffman and Gallaher, 2007; Wagner et al., 2008; Rokaya et al., 2010). Here, the researchers used Rapid Vulnerability Assessment (RVA) technique to identify plants that were vulnerable to over-exploitation. The technique, originally developed by Cunningham (2001) in Uganda, has been used by many researchers in Nepal (Lama et al., 2001; Rokaya, 2002; Ghimire and Aumeeruddy-Thomas, 2005; Wagner et al., 2008). Here, the researchers adopted the modified RVA method of Wagner et al., (2008) that included six indicators: plant parts used in local medicine, life form, local frequency, distribution, intensity of use in Tibetan medicine; and use value: single vs. multiple use. Endangerment value was based on numerical values obtained by adding the final threat values (Table 1).

Table 1: Threat value by indicator and category

\begin{tabular}{|c|c|c|}
\hline Indicator & Category & $\begin{array}{l}\text { Threat } \\
\text { value }\end{array}$ \\
\hline \multicolumn{3}{|l|}{ Life form } \\
\hline & annual/ biennial & 1 \\
\hline & Perennial & 2 \\
\hline & Woody & 3 \\
\hline \multicolumn{2}{|l|}{ parts used } & 1 \\
\hline & $\begin{array}{l}\text { generative organs, } \\
\text { whole above-ground } \\
\text { plant parts, bark }\end{array}$ & 2 \\
\hline & $\begin{array}{l}\text { whole plant, whole } \\
\text { below-ground plant } \\
\text { parts }\end{array}$ & 3 \\
\hline \multicolumn{3}{|l|}{ distribution } \\
\hline & wider distribution & 1 \\
\hline & Himalaya-endemic & 2 \\
\hline & Nepal-endemic & 3 \\
\hline \multicolumn{3}{|c|}{ local frequency } \\
\hline & Frequent & 1 \\
\hline & Moderate frequent & 2 \\
\hline & Rare & 3 \\
\hline \multicolumn{3}{|c|}{ intensity of use } \\
\hline & Occasional & 2 \\
\hline & Frequent & 3 \\
\hline \multicolumn{3}{|l|}{ use value } \\
\hline & Single & 1 \\
\hline & Multiple & 2 \\
\hline
\end{tabular}

\section{Results and discussion}

Indigenous people included in the study area were: Bramin, Chhetri, Newar, Magar, Rai, Kami, and Bhujel. These communities fulfill their daily needs, depending directly or indirectly upon the forest resources. This finding is similar to other findings from different parts of Nepal (Joshi and Edington, 1990; Uprety et al., 2010; Rokaya et al., 2010).

A total of 85 plant species belonging to 79 genera and 46 families were recorded in the study areas. Twelve plant species were used for various purposes other than medicinal. They were used as: food, fodder, in construction, in religious purposes and even in yielding dyes. 
Altogether 73 plant species were found to bear medicinal properties for treating 144 different ailments. When comparing with different literatures (Manandhar, 1985; Acharya, 1996; Adhikari, 1997; Adhikari, 1998; Poudel, 2000; Joshi and Joshi, 2001; Rajbhandari, 2001; Manandhar, 2002; Baral and Kurmi, 2006; DPR, 2007), the researchers found remedies for 27 ailments as new uses (Table 2). None of the plants, recorded in the study, were identified as new medicinal plants, as they have already been reported from different parts of Nepal. The similar kinds of remedies reported from different plants of Dang (three VDCs of the study area) and also from other parts of Nepal show that the information documented in this research are reliable. As the plants are also found to be used in some life threatening ailment such as diabetes (e.g. Aegle marmelos, Sysygium cumini) and asthma (e.g. Datura stramonium, Piper longum), further investigation should be carried out in depth, to find the possibility of such plants being used in broader scales.

The ethnobotanical information was categorized into seven classes: medicinal, food, fodder, construction, fiber, religious and others (colouring, dyes). The medicinal uses were further classified into nine diseases: circulatory, digestive, excretory, muscular, nervous, respiratory, reproductive, skeletal systems and others (cough cold, cuts, wounds, lactation, eye problems, etc

Regarding the categories of medicinal uses, the highest number of plants belonged to the category: others; followed by the category: digestive system; and the category: muscular system (Fig. 1). The category: nervous system; had only one species (Semecarpus anacardium). Medicinal plants were also used for various other purposes such as food, fodder, fiber, construction, religious and others (colouring, dyes).

The different plant parts: roots/rhizomes/bulbs/ tubers, young shoot; stem/bark, leaves, flowers and seeds/fruits were used for different ailments. The medicinal plants were used in different forms of preparations; and the most widely used form was juice (24), followed by soup or tea or food (13), and paste or decoction (12 each). The smoke (2) is the least used type of form; and is used for treating sinusitis (e.g. Colebrookea oppositifolia,
Flemingia procumbens, Woodfordia fruticosa). The most common way of admission of medicine was oral (76.71\%) followed by external or topical $(35.6 \%)$ and nasal (1.27 \%). This finding which is similar to other findings (e.g. Rokaya et al., 2010) indicates that people usually follow the easiest means of mode of admission of medicine.

There are some plants, which are widely used as medicinal plants in various parts of Nepal but not in this study sites. For this reason, such plants were deliberately excluded from medicinal plant category in the results of this study. Examples of such plants are: Elsholtzia flava that is used as condiment in Dang, but is used against scabies (Rajbhandari, 2001; Manandhar, 2002); Lawsonia inermis leaves are crushed to obtain dye for colouring hands, feet and hair in Dang, but the plant is used in toothache, cracks in skin, skin diseases, burns (Manandhar, 2002), jaundice, spleen, skin diseases, leprosy, headache, increase sperms, sore throat, hair tonic (DPR, 2007); Leucaena leucocephala is only used as fodder in Dang, but bark and roots are aborifacient and seeds are emollient in nature (Manandhar, 2002); and Thysanolaena maxima is used only to make broom in Dang, whereas its root paste is applied to treat boils (Rajbhandri, 2001; Manandhar, 2002).

In the present study, many plants were reported as having only a limited number of medicinal uses (usually one or up to three). However, several other studies have found such plants to possess a wide range of uses. For example, Acacia catechu is reported to be used against intestinal worms only, but its stem is also used by the Tharus to treat cough in Dang (Rajbhandari 2001), to treat body pain and skin diseases in Rukum, Dhading, Sindhuli, Makwanpur, Chitwan and Sankhuwashava, Morang (Manandhar, 2002; Rajbhandari, 2001), construction in Bara (Rajbhandari, 2001), and to treat indigestion ulcer in some other parts of Nepal (DPR, 2007) (Table 1).

The RVA result showed that scores ranged from 7-15. Dalbergia sissoo is found to be highly vulnerable with 15 scores. It was followed by Terminalia alata (14 scores). Three species: Calotropis gigantea, Euphorbia thymifolia, and Oxalis corniculata each with the least score 1 were widely distributed (Table 2). Wagner et al. (2008) found that there were 7 species of plants out of 102 species with high potential 
endangerment whereas Lama et al. (2001) pointed out that there were 24 species to be potentially vulnerable out of 136 species of absolutely needed by Traditional Health Care centre in lower Dolpa and Rokaya (2002) pointed out that there were 21 plant species as potentially vulnerable from Upper Dolpa. The RVA-test in the present analysis showed that possibly 9 plant species with high scores are potentially vulnerable. A detailed study is needed for formulating a pragmatic plan to conserve these vulnerable plants. The plan should be formulated in accordance with local interest as well as the available resources. Uprety et al. (2010) prioritized 10 plant species (out of 101) plant species from Bardiya, Terai region similar to Dang.

\section{Conclusion}

The forest resources play vital role in daily life of the people of Dang district. They need domestication and commercialization in boarder scale. Till today, indigenous knowledge has continued to be transferred verbally. Now, it needs proper documentation. phytochemical or pharmacological studies have also become necessary to explore the potential of plants used for medicinal purposes. In order to develop sustainable harvesting techniques, proper techniques and awareness programmes are necessary. Any benefits that are obtained from the present knowledge should be equally shared with indigenous people because the documented knowledge in the present paper is actually their valuable asset.

\section{Acknowledgements}

The authors are thankful to the local people for their hospitality and sharing their information on indigenous knowledge about uses of plant resources and also authorities of National Herbarium and Plant Laboratories (KATH), Godawari for their help in the identification of unknown plant species. We also appreciate invaluable suggestions and help of Binu Timsina during manuscript writing.

\section{References}

Acharya, S. K. 1996. Folk uses of some medicinal plants of Pawannagar, Dang district. J. of Nat. Hist. Museum 15: 25-36.
Adhikari, K. 1997. Indigenous healing practices in Nepal: A case study of the Tharus in Amrai village, Dang. M. A. dissertation, Central Dept. of Sociology/Anthropology, Tribhuvan University, Kirtipur, Nepal.

Adhikari, S. M. 1998. Health Care by Local Herbal Resources (Sthaniya Jadibuti Dwara Swasthya Racchya). Mahendra Sanskrit University, Dang, Nepal.

Baral, S. R., and Kurmi, P. P. 2006. A Compendium of Medicinal Plants in Nepal. Mrs Rachana Sharma, Kathmandu, Nepal.

CBS. 2001. Statistical Year Book. Central Bureau of Statistics, Government of Nepal, Kathmandu, Nepal.

Chaudhary, R. P. 1998. Biodiversity in Nepal: Status and Conservation. Know Nepal series No. 17, S. Devi, Saharanpur, India.

Cunningham, A. B. 2001. Applied Ethnobotany: People, Wild Plant use and Conservation. A People and Plant Conservation Manual, Earthscan, London, UK.

DPR. 2007. Medicinal Plants of Nepal (Revised). Bull. Dept. Plant Resources. No. 28, Ministry of Forests and Soil Conservation, Kathmandu Nepal.

Ghimire, S. K., and Aumeeruddy-Thomas, Y. 2005 . Approach to in situ conservation of threatened Himalayan medicinal plants: a case study from Shey-Phoksundo National Park, Dolpo. In Himalayan medicinal and aromatic plants: balancing use and conservation (eds) AumeeruddyThomas, Y., Karki, M., Parajuli, D. and Gurung, K., IDRC Canada, WWF Nepal, and UNESCO/WWF People and Plants Initiative, 209-234.

Hoffman, B. and Gallaher, T. 2007. Importance indices in ethnobotany. Ethnobotany Research and Applications 5: 201-218.

Joshi, K. K. and Joshi, S. D. 2001. Genetic Heritage of Medicinal and Aromatic Plants of Nepal Himalaya. Buddha Academic Publishers and Distributors Pvt. Ltd., Kathmandu, Nepal. 
Joshi, A. R. and Edington, J. M. 1990. The use of medicinal plants by two village communities in the central development region of Nepal. Economic Botany 44: 71-83.

Lama, Y.C., Ghimire, S. K., AumeeruddyThomas, A. 2001. Medicinal Plants of Dolpo: Amchis' Knowledge and Conservation. People and Plants Initiative and WWF Nepal Program, Kathamandu, Nepal.

Manandhar, N. P. 2002. Plants and People of Nepal. Timber Press Portland, Oregon., USA.

Manandhar, N.P. 1985. Ethnobotanical notes on certain medicinal plants used by Tharus of Dang-Deokhuri district, Nepal. Int. J. Crude Drug. Res. 23 (4): 153-159.

Martin. G.J. 1995. Ethnobotany: A Methods Manual. Chapman and Halls, London, UK.

Polunin, O. and Stainton, A. 1984. Flowers of the Himalaya. Oxford University Press, New Delhi, India.

Poudel, S.K. 2000. Ethnobotanical Study of the Tharus Living in Central part of Dang (Mid-western Nepal). M. Sc. Dissertation, Central Department of Botany, Tribhuvan University, Kirtipur, Nepal.

Press, J. R., Shrestha, K. K., and Sutton, D. A. 2000. Annotated Checklist of Flowering Plants of Nepal. The Natural History Museum, London, UK.
Rajbhandari, K.R. 2001: Ethnobotany of Nepal. Ethnobotanical Society of Nepal, Kathmandu , Nepal.

Rokaya, M. 2002. Ethnoecology of Medicinal Plants in Dho-Tarap Area in the Bufferzone of Shey Phoksundo National Park, Dolpa, Nepal. M.Sc. Dissertation. Central Department of Botany, Tribhuvan University, Kirtipur, Nepal.

Rokaya, M. B., Munzbergova, Z. and Timsina, B. 2010. Ethnobotanical study of medicinal plants from the Humla district of western Nepal. Journal of Ethnopharmacology 185 (3): 485-504.

Uprety, Y., Boon, E.K., Poudel, R.C., Shrestha, K.K., Rajbhandary, S., Ahenken, A. and Tiwari, N. N. 2010. Non-timber forest products in Bardiya district of Nepal: Indigenous use, trade and conservation. Journal of Human Ecology 30 (3): 143-158.

Wagner, A., Kriechbaum, M. and Koch, M.A. 2008. Applied vulnerability assessment of useful plants: A case study of Tibetan medicinal plants from Nepal. Botanische Jabrbücher für Systematik 127 (3): 1-29. 


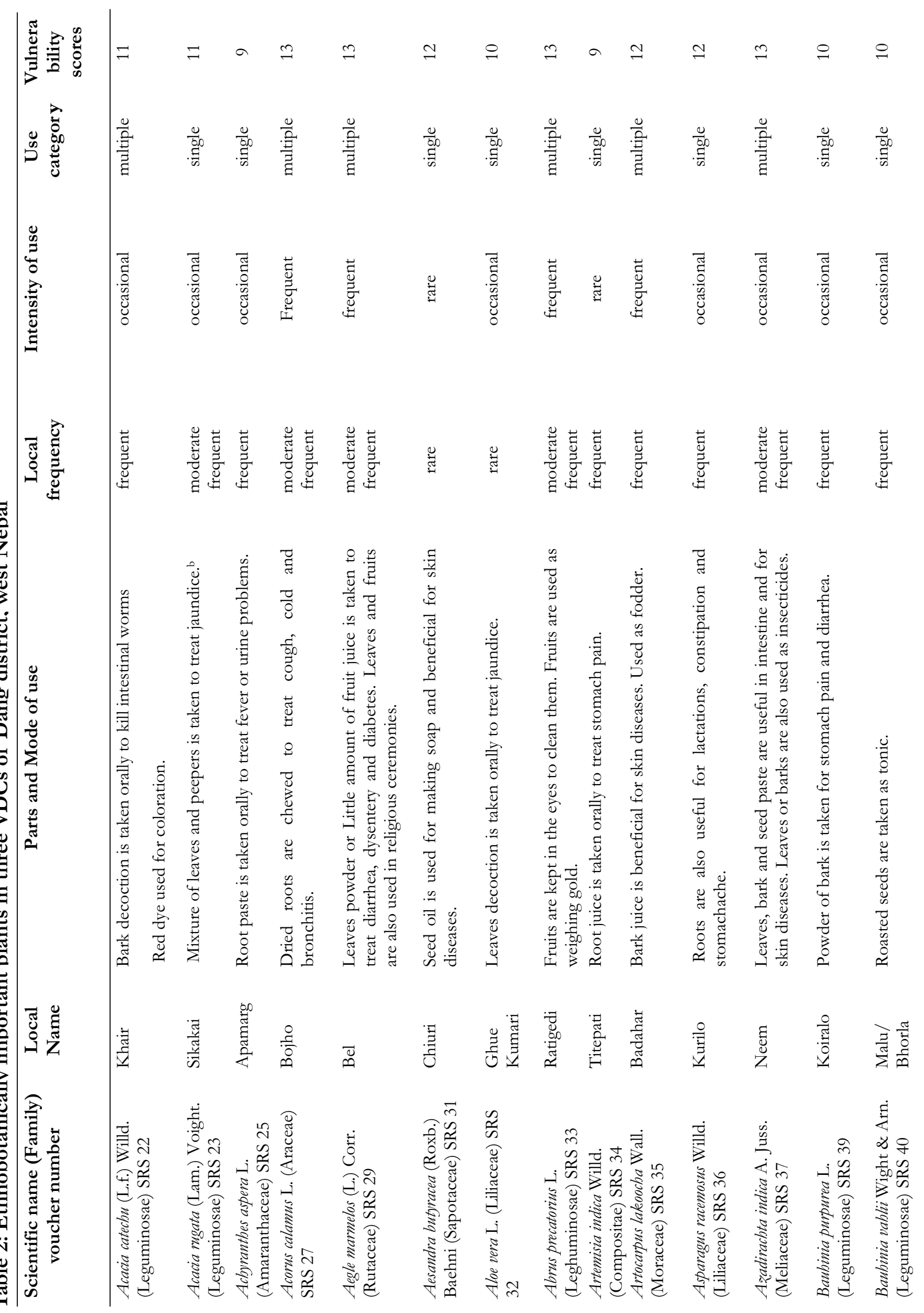




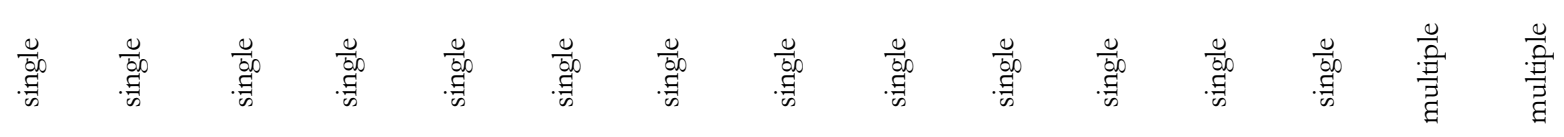

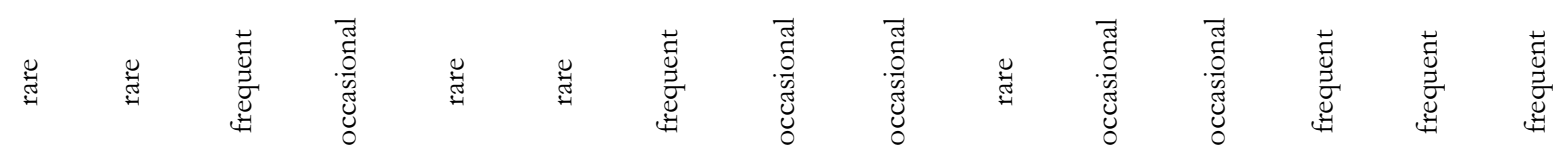

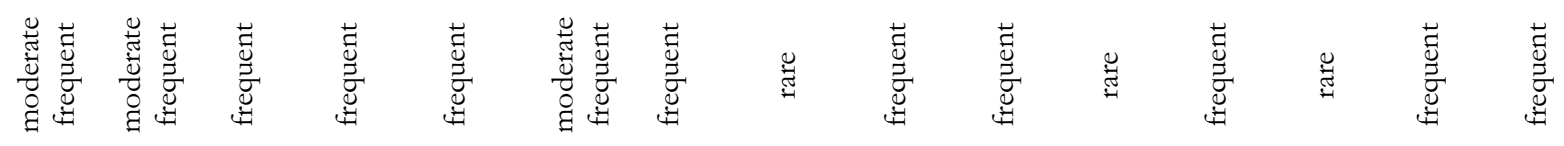

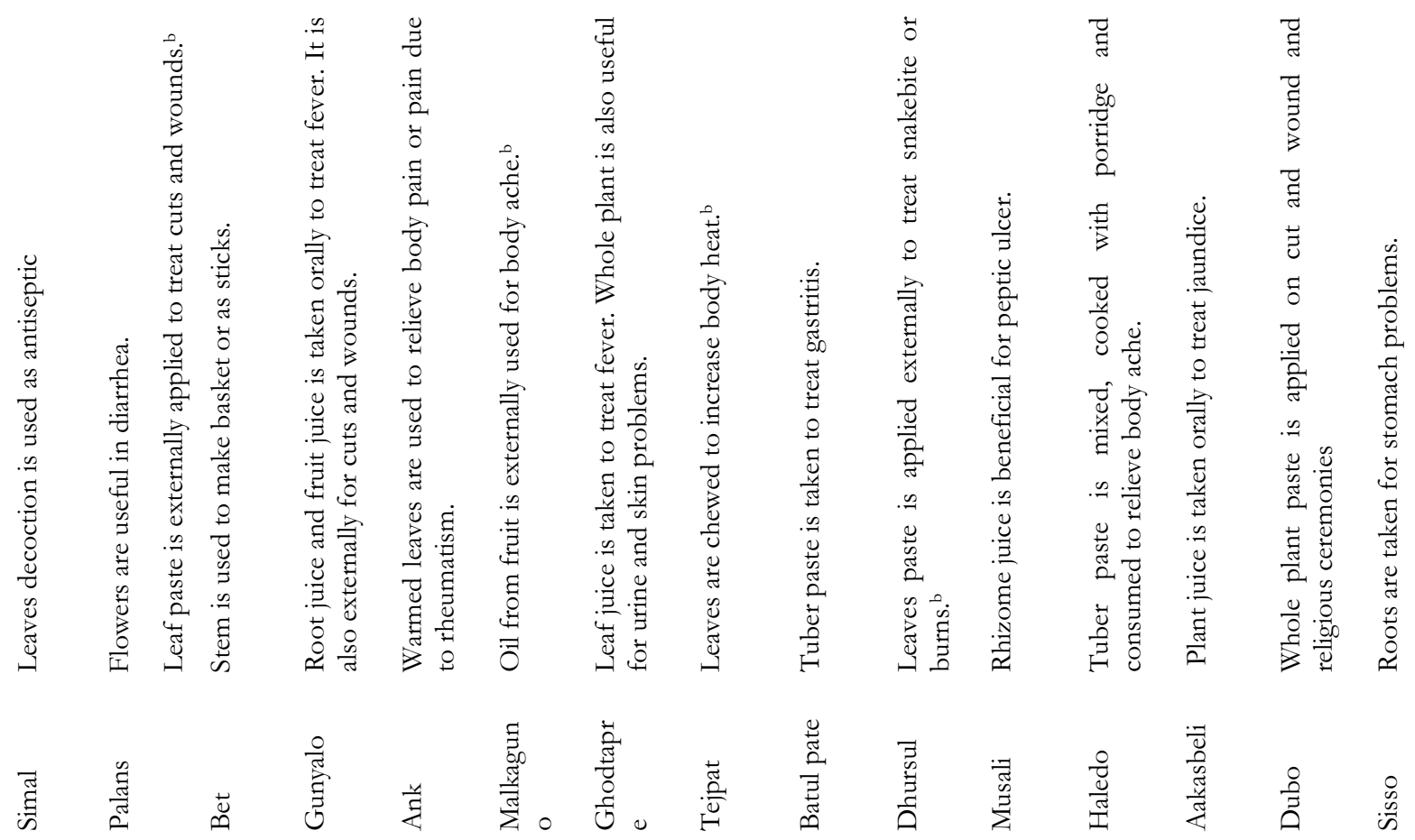

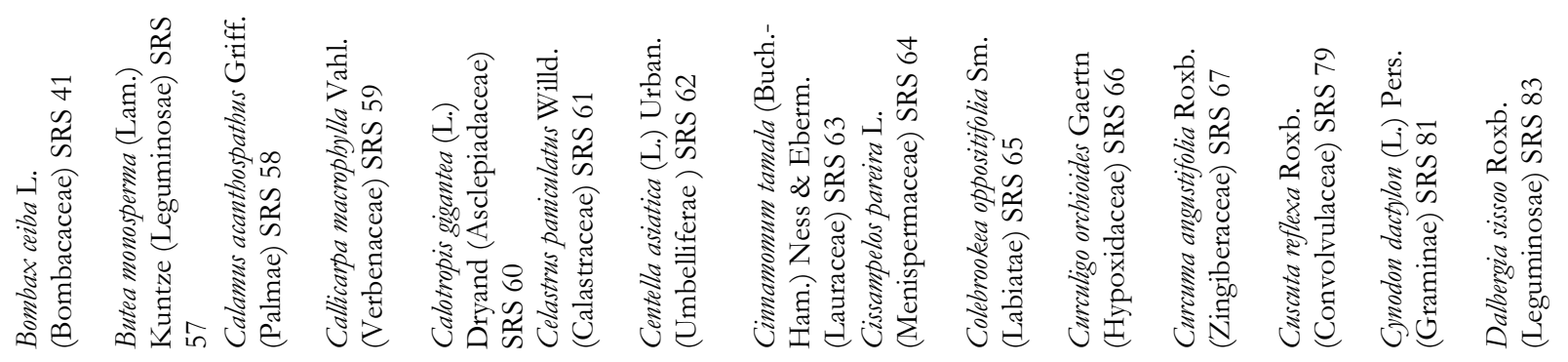




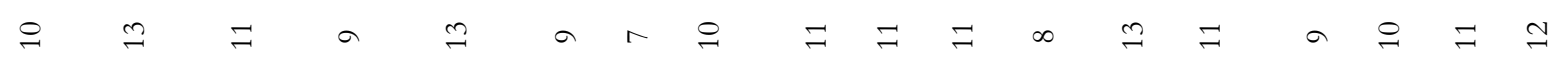

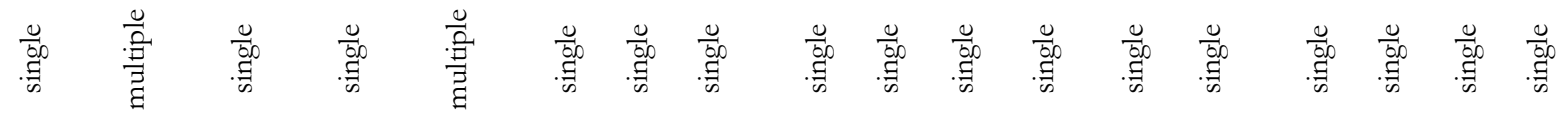

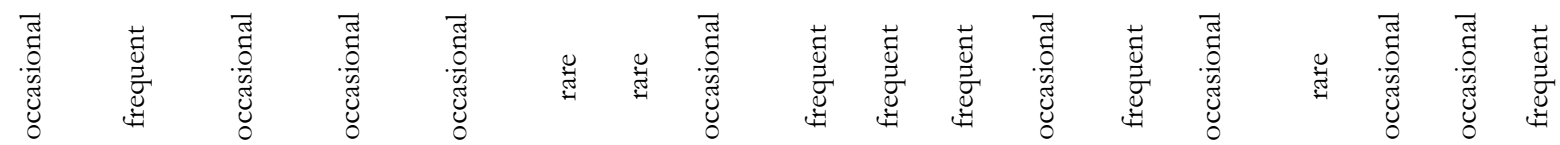

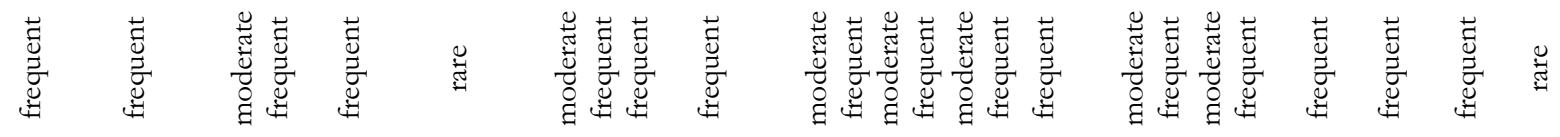

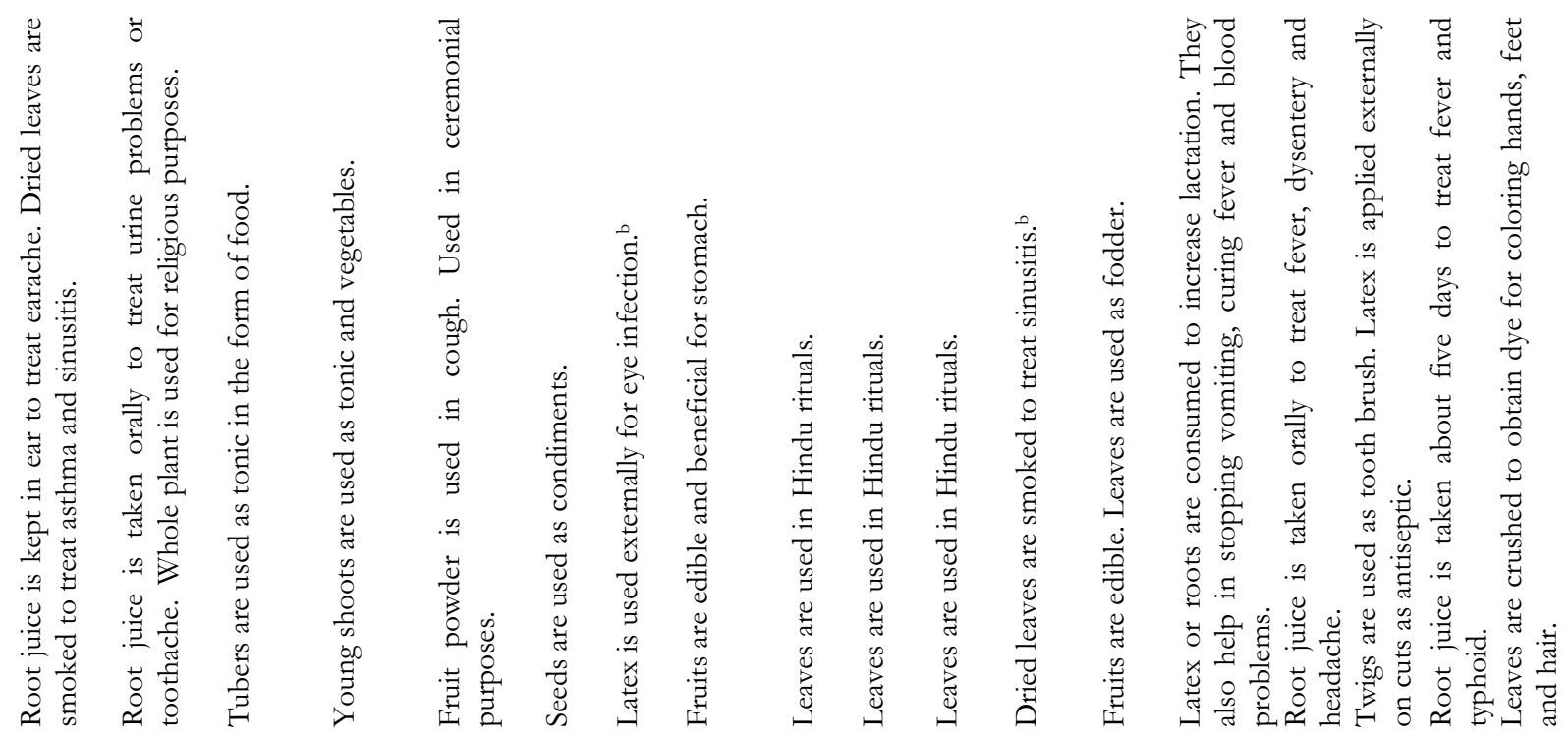

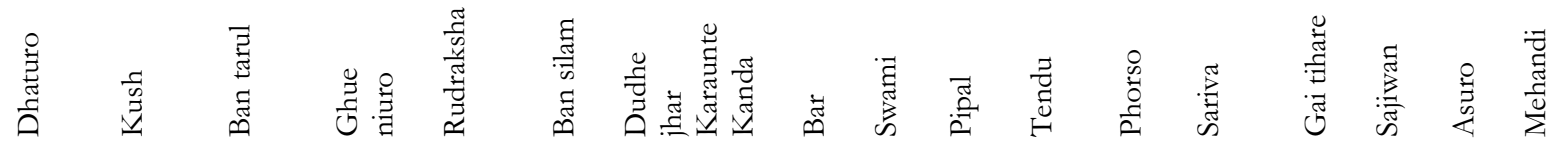

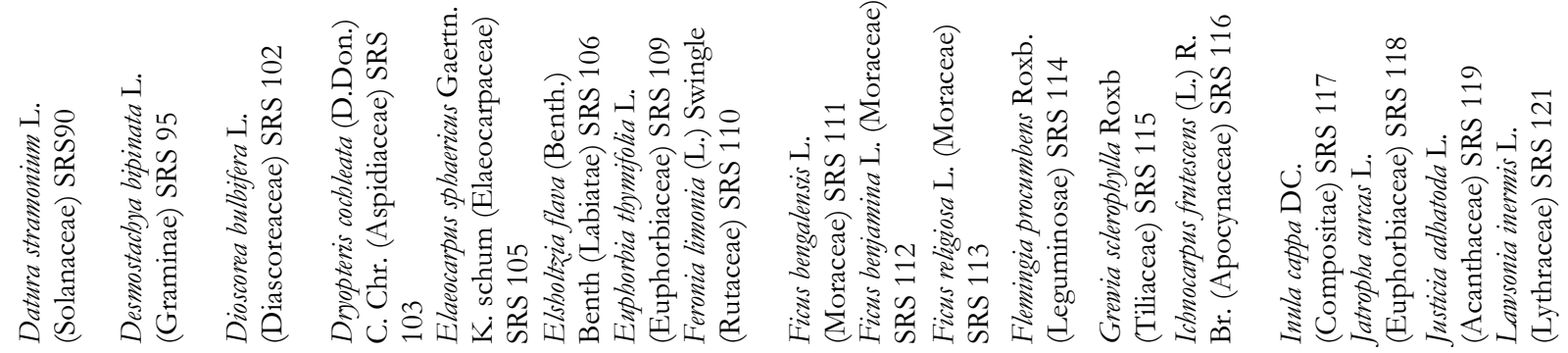




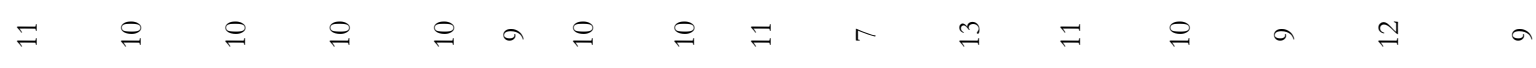

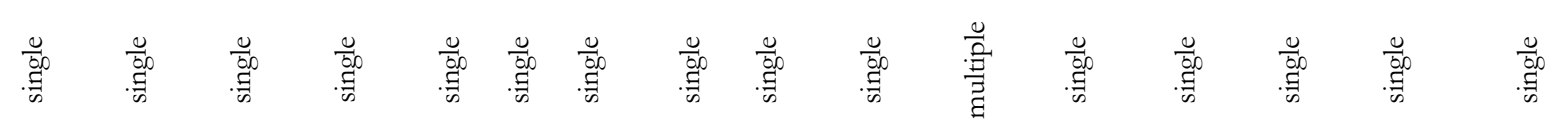

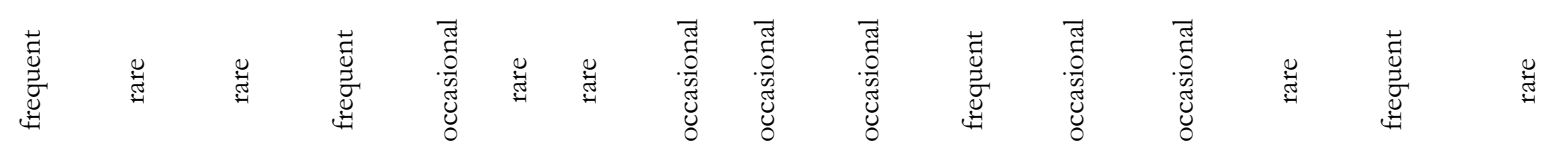

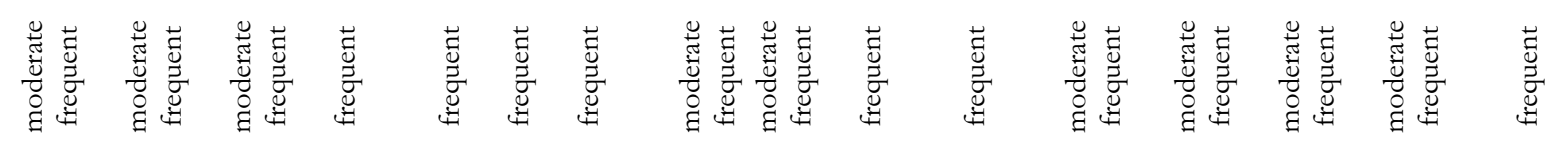

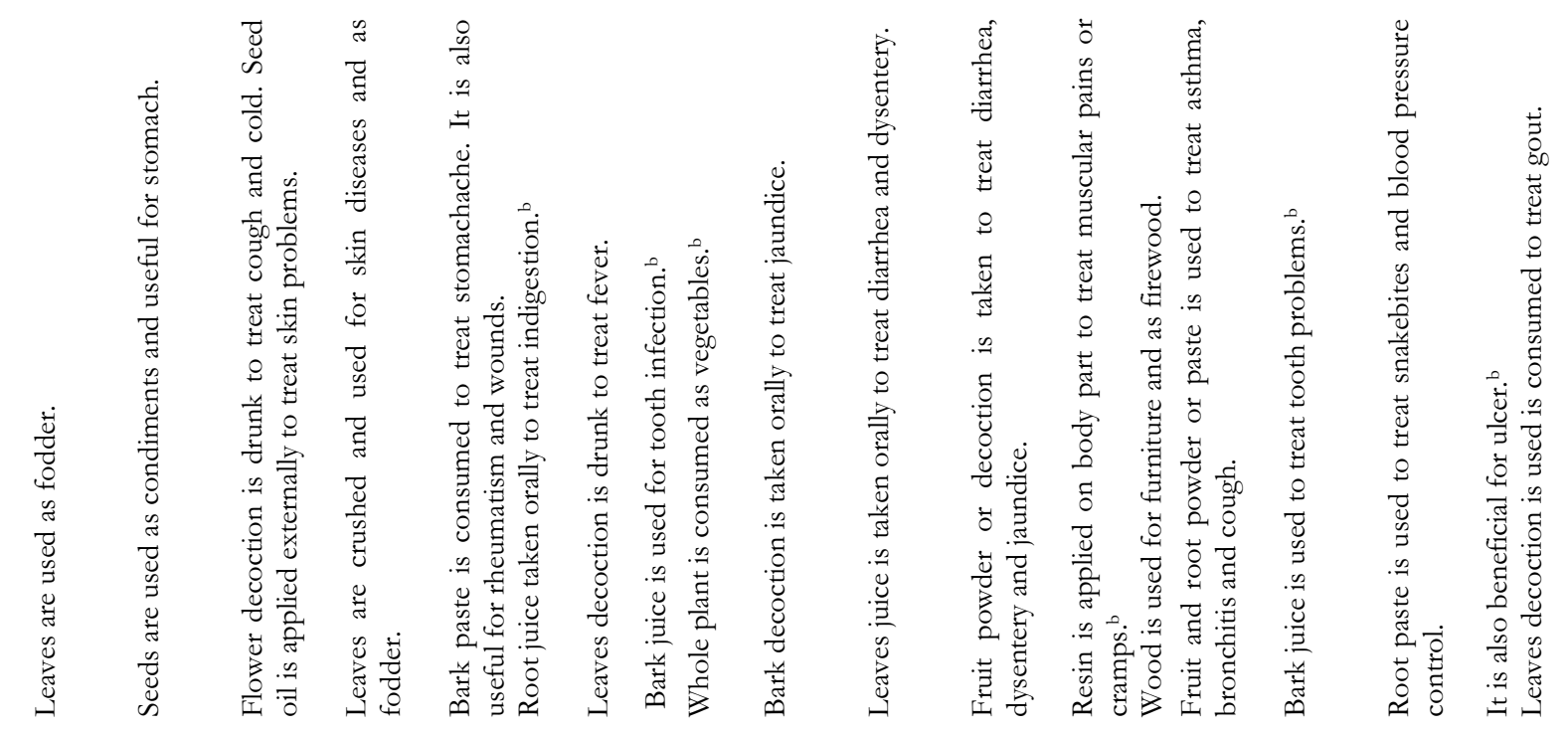

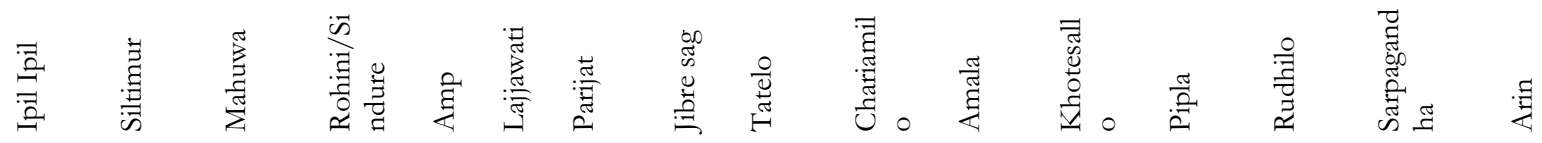

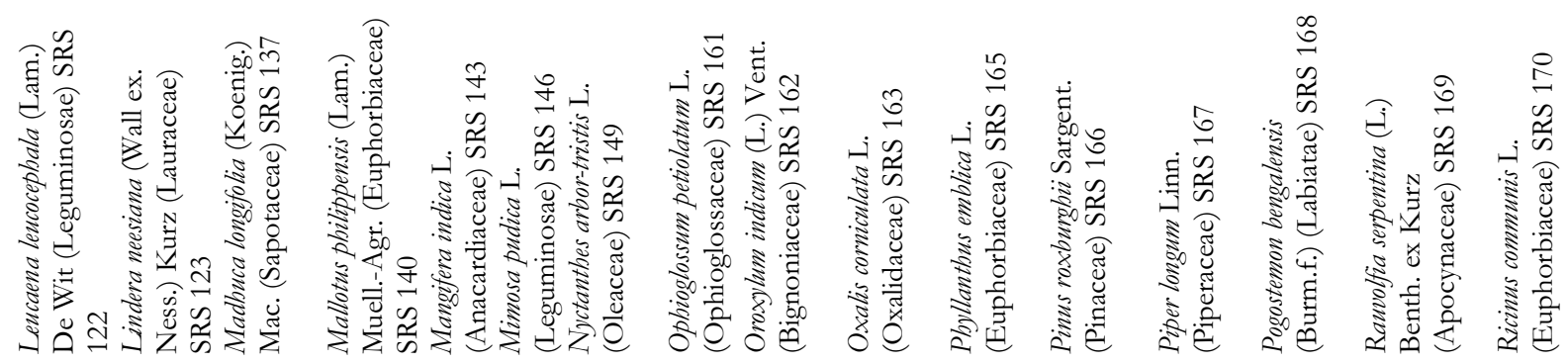




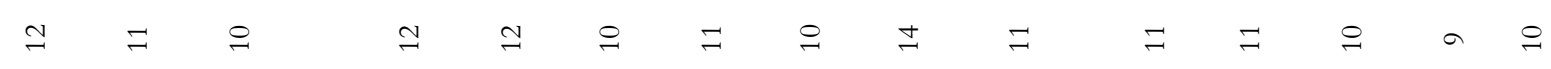

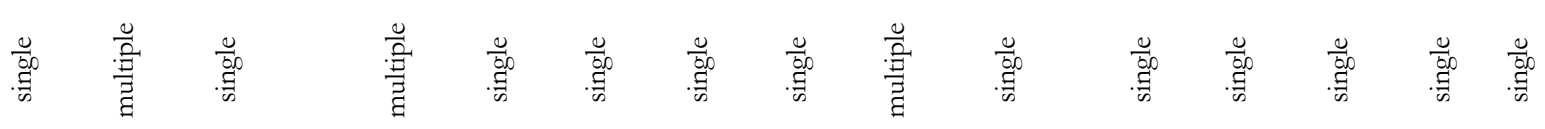

$\|:\| 111111 \| 11$

\|\|$\amalg\|\square\|\|\|\|\|\|\|\|\| \amalg$

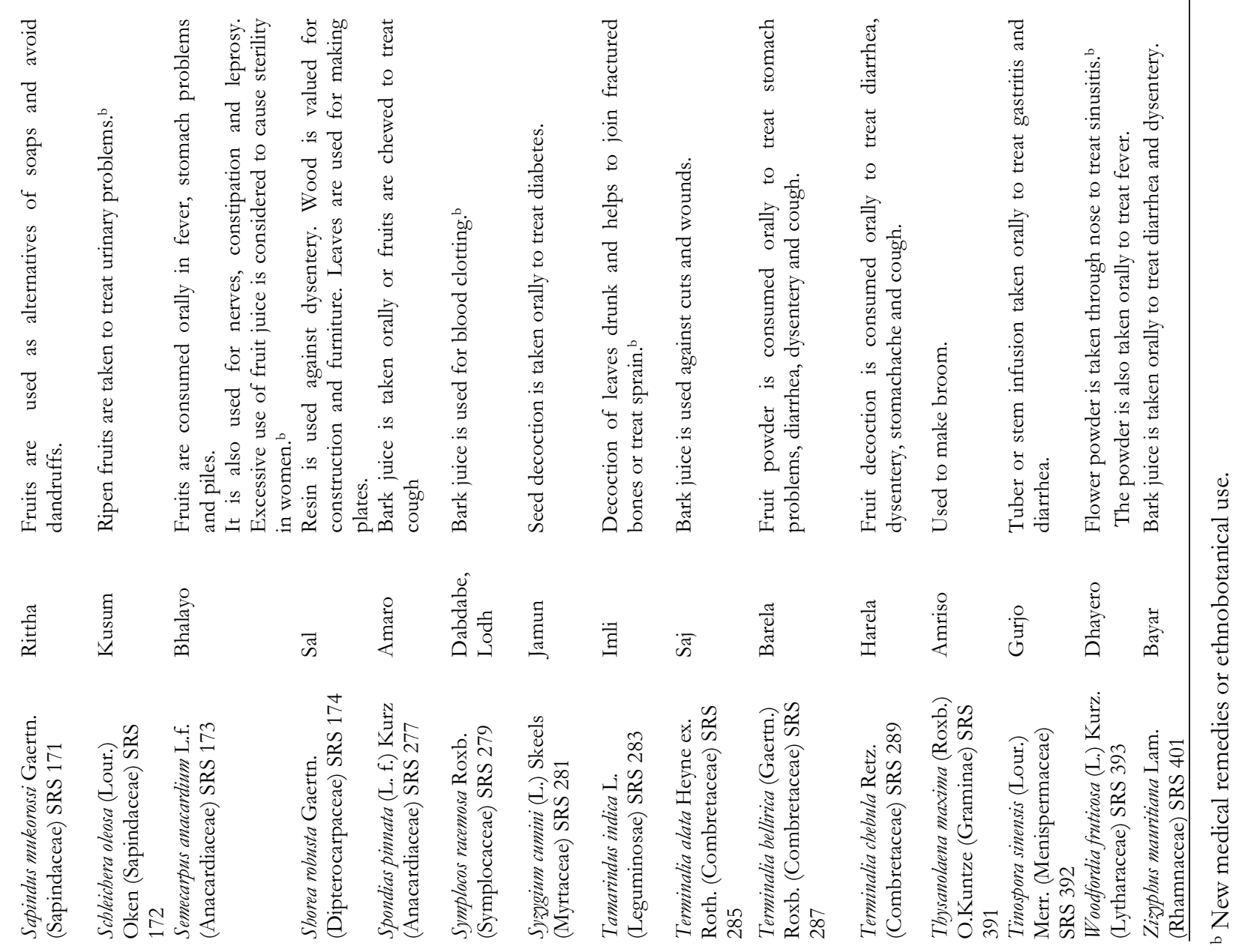

